medRxiv preprint doi: https://doi.org/10.1101/2020.10.19.20215681; this version posted November 10, 2020. The copyright holder for this preprint (which was not certified by peer review) is the author/funder, who has granted medRxiv a license to display the preprint in perpetuity. All rights reserved. No reuse allowed without permission.

\title{
Discussion of Mental IIIness and Mental Health By NBA Players on Twitter
}

Authors: Shaan Kamal ${ }^{*}$, M.S. ${ }^{1}$, Shahan Kamal, B.S. ${ }^{2}$, Osama El-Gabalawy ${ }^{*}$ M.S. ${ }^{3}$

${ }^{*}$ Equal contributions

${ }^{1}$ University of Connecticut School of Medicine, 263 Farmington Avenue, Farmington CT, USA 06030

${ }^{2}$ University of Connecticut, Storrs, CT 06269

${ }^{3}$ Stanford University School of Medicine, 291 Campus Drive, Stanford, CA 94305

\section{Corresponding Author:}

Shaan Kamal

University of Connecticut School of Medicine

263 Farmington Avenue

Farmington, CT, 06030, USA

Tel: 845-857-9746

Email: skamal@uchc.edu

\begin{abstract}
In 2019, the National Basketball Association (NBA) expanded it's mental health rules to include mandating that each team have at least one mental health professional on their full-time staff and to retain a licensed psychiatrist to assist when needed. In this work, we investigate the NBA players' discussion of mental health using historical data from players' public Twitter accounts. All current and former NBA players with Twitter accounts were identified, and each of their last 800 tweets were scraped, yielding 920,000 tweets. A list of search terms derived from the DSM5 diagnoses was then created and used to search all of the nearly one million tweets. In this work, we present the most common search terms used to identify tweets about mental health, present the change in month-by-month tweets about mental health, and identify the impact of players discussing their own mental health struggles on their box score statistics before and after their first tweet discussing their own mental health struggles.
\end{abstract}

Word Count: 787

Keywords: Depression, Anxiety, Sports Psychiatry

\section{Introduction:}

Although sports psychiatry is not a new area within psychiatry, athlete mental health has become a more prevalent topic of discussion as many successful, world renowned athletes have discussed their own mental health struggles. ${ }^{1,2,3}$ Despite the ongoing discussions of mental health in this population, there is little in the way of literature on the topic or any quantifying such 
medRxiv preprint doi: https://doi.org/10.1101/2020.10.19.20215681; this version posted November 10, 2020. The copyright holder for this preprint (which was not certified by peer review) is the author/funder, who has granted medRxiv a license to display the preprint in perpetuity.

disclosures by athletes. The literature on psychiatric treatment of athletes in professional organizations is also limited, but in 2019, the National Basketball Association (NBA) expanded it's mental health rules to include mandating that each team have at least one mental health professional on their full-time staff and to retain a licensed psychiatrist to assist when needed. ${ }^{4}$ These measures were a response to increasing player discussions of mental health on social media platforms. In this work, we investigate the NBA players' discussion of mental health using historical data from players' public Twitter accounts.

\section{Methods}

All current and former NBA players with Twitter accounts were identified using BasketballReference, and each of their last 800 tweets were scraped on June 15th, 2020. Tweets collected included retweets from other accounts not written by the player himself. A list of search terms derived from the DSM5 diagnoses was then created and used to search all of the tweets that were collected (see Figure 1 for the full list of search terms used). In this work, we present the most common search terms used to identify tweets about mental health, present the change in month-by-month tweets about mental health, and identify the impact of players discussing their own mental health struggles on their box score statistics before and after their first tweet discussing their own mental health struggles.

\section{Results}

In total, 1,453 Twitter accounts were found for current and former NBA players. Next, up to 800 of each player's most recent tweets were collected, with 1,374 of the 1,453 players with Twitter accounts having tweeted at least once (accounts that did not have tweets collected were due to the accounts being deactivated or set to private). There were a total of 920,000 tweets collected. Using the search terms to search every tweet, 1,172 tweets were found to contain at least one mental health term. Of the players with a Twitter account, 520 players (38\%) tweeted about mental health.

When looking at the chronology of the tweets, there is a clear trend of an increasing number of positive tweets each year with a large increase in 2018, coinciding with the first NBA player to disclose his own mental health struggles in a tweet during March of 2018 (Figure 2). Other important events from 2018 onwards are the NBA's Autism Awareness Month and the beginning of the lockdown period following the COVID-19 epidemic in March of 2020 (Data was collected halfway through 2020, but the number of mental health tweets in 2020 found was already nearly equivalent to the total number of tweets from 2019.

The tweets were then analyzed to determine which search term was most common within the subset of tweets about mental health (Figure 3). The most common term was "autism", with several players tweeting and retweeting about Autism Awareness Month in addition to a player raising awareness due to his son having autism. The next most common terms are anxiety, suicide, and depression.

We next worked to determine if there was any correlation and potential impacts of a player disclosing his own mental health struggles instead of tweeting about mental health topics in general. This was done by reading each of the 1,172 tweets about mental health to determine if any player was disclosing their own mental health struggles. Two players were found to have 
tweeted disclosing their own mental health struggles. These players' performance in the 10 games before and after their first tweet disclosing their own was compared using BasketballReference's box scores (Figure 4). Both players had better performance in the 10 games after in almost all categories (points, field goals made, field goals attempted, field goal percentage, 3 point shots made, 3 point shots attempted, 3 point percentage, free throws made, free throws attempted, free throw percentage, offensive and defensive rebounds, true rebounds, assists, blocks,game score, and plus/minus) although both also had increases in personal fouls, and turnovers and player 2 showed no change in his steals.

\section{Discussion}

Sports psychiatry is a growing field, with increasing literature on psychiatrists working with professional organizations and data on treatments. This work adds to the literature in showing quantitatively how the discussion amongst professional athletes regarding mental health has changed over time, what that discussion focuses on, and the potential impact of disclosing one's own mental health struggles on performance.

\section{Disclosure Statement:}

The authors declare no competing interests.

\section{References}

1. Begel, Daniel. "An overview of sport psychiatry." Am J Psychiatry 149.5 (1992): 606-614.

2. Arvinen-Barrow, M. (2016). Commentary: the experience of depression during careers of elite male athletes. Frontiers in psychology, 7, 1609.

3. Ströhle, A. (2019). Sports psychiatry: mental health and mental disorders in athletes and exercise treatment of mental disorders. European archives of psychiatry and clinical neuroscience, 269(5), 485-498.

4. McDuff, D. R., \& Garvin, M. (2016). Working with sports organizations and teams. International review of psychiatry, 28(6), 595-605.

Author Contributions: SK and OE both developed the methodology, analyzed results, and wrote and edited the final manuscript. 
medRxiv preprint doi: https://doi.org/10.1101/2020.10.19.20215681; this version posted November 10,2020 . The copyright holder for this
preprint (which was not certified by peer review) is the author/funder, who has granted medRxiv a license to display the preprint in perpetuity. All rights reserved. No reuse allowed without permission.

\section{Figures}

\section{Figure 1: Search Terms:}

['autism', 'autistic', 'attention-deficit/hyperactivity', 'adhd', 'attention deficit disorder', 'ad/hd', 'attention d eficit hyperactivity', 'schizophrenia', 'schizophrenic', 'schizotypal', 'schizophreniform', 'schizoaffective', 'psych otic', 'delusional disorder', 'catatonia', 'catatonic', 'bipolar', 'cyclothymic', 'cyclothymia', 'depressive disorde r', 'depression', 'depressed', 'disruptive mood', 'mood dysregulation', 'major depressive', 'persistent depressive', 'depressive disorder', 'dysthymia', 'dysthymic', 'anxiety', 'anxiety disorder', 'social anxiety', 'separation anxiet y', 'mutism', 'phobia', 'social phobia', 'panic disorder', 'panic attack', 'agoraphobia', 'generalized anxiety', 'sub stance/medication-induced anxiety disorder', 'obsessive-compulsive', 'obsessive compulsive', 'ocd', 'body dysmorphi c', 'body dysmorphia', 'hoarding disorder', 'hoarder', 'trichotillomania', 'hair-pulling', 'hair pulling', 'excoriati on', 'skin-picking', 'skin picking', 'reactive attachment', 'disinhibited social engagement', 'posttraumatic stress', 'ptsd', 'post traumatic stress', 'acute stress disorder', 'adjustment disorder', 'dissociative identity disorder', 'd issociative amnesia', 'depersonalization', 'derealization', 'somatic symptom', 'somatic disorder', 'illness anxiety d isorder', 'conversion disorder', 'functional neurological symptom disorder', 'neurological disorder', 'neurological s ymptom disorder', 'factitious disorder', 'pica rumination', 'avoidant food intake', 'restrictive food intake', 'anore xia nervosa', 'anorexia', 'anorexic', 'bulimia nervosa', 'bulimia', 'bulimic', 'binge eat', 'binge-eat', 'sleep terro r', 'nightmare disorder', 'sexual dysfunction', 'delayed ejaculation', 'erectile disorder', 'erectile dysfunction', 'orgasmic disorder', 'sexual interest disorder', 'sexual arousal disorder', 'genito-pelvic pain', 'penetration disord er', 'hypoactive sexual desire', 'gender dysphoria', 'oppositional defiant', 'intermittent explosive', 'conduct disor der', 'personality disorder', 'antisocial personality', 'pyromania', 'kleptomania', 'alcoholism', 'alcoholic', 'alcoh ol use disorder', 'alcohol intoxication', 'alcohol withdrawal', 'alcoholic seizures', 'phencyclidine use disorder', 'opioid use disorder', 'opioid intoxication', 'opioid withdrawal', 'gambling disorder', 'delirium', 'delirious', 'par anoid personality', 'antisocial personality', 'borderline personality', 'histrionic personality', 'narcissistic perso nality', 'avoidant personality', 'dependent personality', 'obsessive-compulsive personality', 'voyeuristic', 'exhibit ionistic', 'frotteuristic', 'sexual masochism', 'sexual sadism', 'pedophilic', 'pedophilia', 'pedophile', 'fetishisti c', 'transvestic', 'drug addict', 'heroin addict', 'crack addict', 'meth addict', 'cocaine addict', 'weed addict', 'c annabis addict', 'marijuana addict', 'alcohol addict', 'opiate addict', 'hallucinogen addict', 'substance use disorde r', 'substance abuse', 'heroin intoxication', 'crack intoxication', 'meth intoxication', 'cocaine intoxication', 'wee d intoxication', 'marijuana intoxication', 'alcohol intoxication', 'opiate intoxication', 'cannabis intoxication', 'h allucinogen intoxication', 'mental disorder', 'alcoholic', 'suicide', 'suicidal', 'psychiatrist', 'lobotomy', 'mental illness', 'mentally ill', 'mental institution', 'psych ward', 'narcissistic', 'mentalhealth']

\section{Figure 2:Number of Mental Health Tweets by Year}

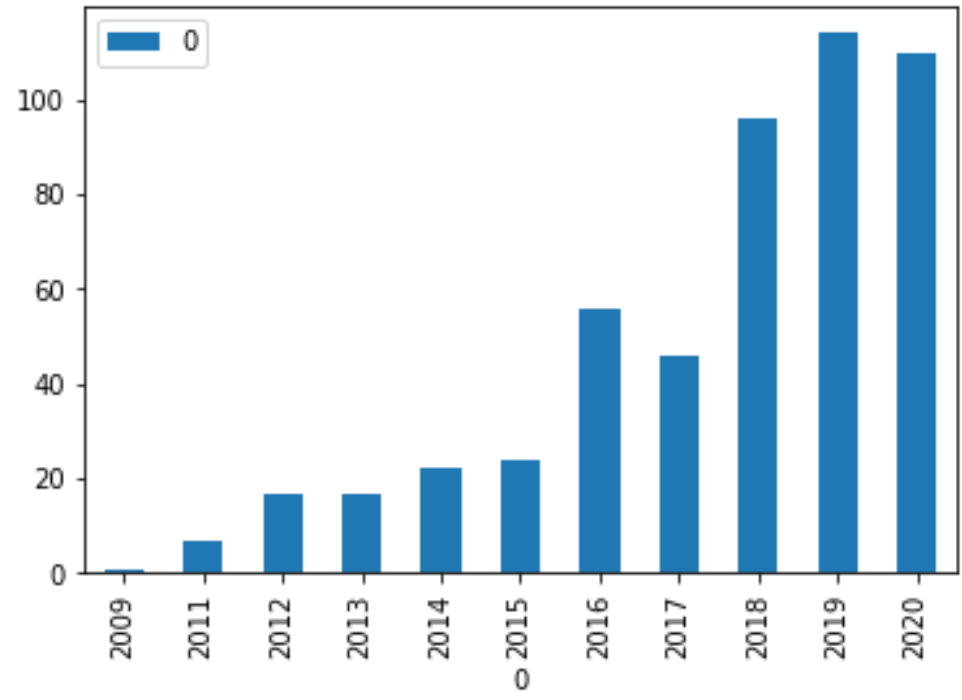


medRxiv preprint doi: https://doi.org/10.1101/2020.10.19.20215681; this version posted November 10, 2020. The copyright holder for this preprint (which was not certified by peer review) is the author/funder, who has granted medRxiv a license to display the preprint in perpetuity.

All rights reserved. No reuse allowed without permission.

Figure 3: Most Commonly Found Search Terms

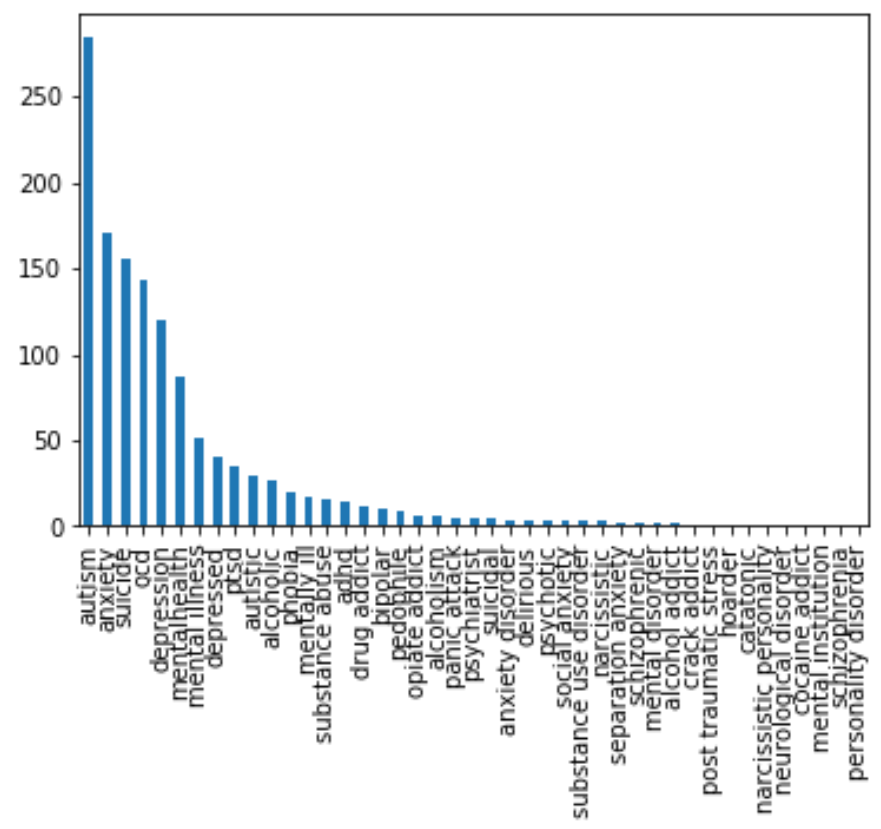

Figure 4: Players' performance difference in the 10 games after disclosing personal mental health struggles compared to the 10 games afterwards

\begin{tabular}{|c|c|c|}
\hline & Player 1 & Player 2 \\
\hline FG & 1.424242 & 1.416667 \\
\hline FGA & 2.636364 & 0.083333 \\
\hline FG\% & 0.042818 & 0.097167 \\
\hline $3 \mathrm{P}$ & 1.409091 & 0.166667 \\
\hline 3PA & 2.030303 & 0.75 \\
\hline $3 \mathrm{P} \%$ & 0.183909 & 0.042 \\
\hline FT & 1.287879 & 1.916667 \\
\hline FTA & 1.583333 & 2.416667 \\
\hline FT\% & 0.040727 & 0.069667 \\
\hline ORB & 0.234848 & 0.083333 \\
\hline DRB & 1.5 & 1.25 \\
\hline TRB & 1.734848 & 1.333333 \\
\hline AST & 1.106061 & 0.833333 \\
\hline STL & 0.159091 & $\underline{0}$ \\
\hline BLK & 0.05303 & 0.25 \\
\hline TOV & 1.136364 & 1 \\
\hline $\mathrm{PF}$ & 0.272727 & 0.25 \\
\hline PTS & 5.545455 & 4.583333 \\
\hline GAME_SCOP & 4.634848 & 3.466667 \\
\hline$+/-$ & 1.606061 & 4.166667 \\
\hline
\end{tabular}

